\title{
Investigating the Academic and Social Benefits of Extended New Student Orientations for First-Year Students
}

\author{
Krista M. Soria, Beth M. Lingren Clark, and Laura Coffin Koch
}

In this study, researchers examined the benefits of college students' participation in an extended new student orientation at a large, public research university. Framed within social identity theory, this study extends a hypothesis that extended new student orientations promote the institutional social identity of first-year students and facilitate their sense of belonging through supportive community development; consequently, the findings suggested that first-year students who participated in an extended new student orientation had a greater sense of belonging, higher academic performance (as measured through students' fall and spring cumulative grade point averages), and higher retention to their second year. Recommendations for new student orientation practitioners, directors, and administrators are discussed.

Student participation in college orientation programs continues to grow across higher education institutions; furthermore, colleges and universities are expanding their efforts to reach and engage first-year students by increasingly offering new modes of orientation, such as virtual orientations, and extending the length of orientations. According to a large, multi-institutional survey of institutional student retention practices administered by the College Board (2011), 64.7\% of responding institutions reported that more than $75 \%$ of first-year students completed all phases of the institution's orientation programming. Barefoot (2005) noted that some form of new student orientation programming occurs at $96 \%$ of higher education institutions. Many of these programs are intentionally designed to provide an extensive experience for first-year students, with close to half of the institutions reporting that they have orientation programs lasting three days or more (College Board, 2011).

New student orientation programs differ in many ways; for example, some institutions offer single day orientation programs that occur immediately preceding the fall semester, while others offer extended orientations often lasting an entire week (NODA Databank, 2011). In addition, approximately one-third of institutions

Krista M. Soria (ksoria@umn.edu) is an Analyst in the Office of Institutional Research at the University of Minnesota.

Beth M. Lingren Clark (lingr004@umn.edu) is the Director of Orientation \& First-Year Programs at the University of Minnesota.

Laura Coffin Koch (koch@umn.edu) is the Associate Vice Provost in the Office of Undergraduate Education at the University of Minnesota. 
offer hybrid models (NODA Databank, 2011), bringing students to campus during the summer to receive campus tours and register for classes and supplementing the transition to students' first-year by offering more extensive programming the week before classes begin. Yet, with so many institutions using either hybrid orientation or extended orientation models, research on the effectiveness of these types of extended orientation remains relatively scant. According to Mayhew, Stipeck, and Dorow (2011), "Despite the near ubiquity of these programs on college campuses, few empirical studies have attempted to address orientation programs and their influence on college students" (p. 54). There is a clear gap in research that investigates extended new student orientations-orientation sessions that last a week or longer that offer an extensive transition experience for new first-year students. The purpose of this research study is to ascertain the benefits of participation in an extended orientation program at a large, public research university in the Midwest. Outcomes examined include first-year students' sense of belonging, fall and spring cumulative grade point averages, and first-to-second year retention.

\section{Literature Review}

Pascarella and Terenzini (1991) noted the importance of a relevant introduction to campus for traditional first-year students, who are often at a developmental crossroads in their lives. An orientation program can provide such an introduction for new students and contribute positively to their transition. Institutions have a very small window of opportunity to establish strong connections with students, as $75 \%$ of non-returning students will withdraw during or immediately following their first semester (Tinto, 1993; Gardner, 1986); therefore, first-year student programs, including new student orientation, are critically important to higher education institutions because they are wellpositioned to make the most positive impact on overall student retention.

New student orientation is intentionally designed to integrate students into the academic and social fabric of the campus community; as gatekeepers to institutional culture and context, orientation programs promote student success and development. Mullendore and Banahan (2005) noted the many roles and functions new student orientation serves on campus, promoting orientation as "the college's best opportunity to introduce a strong learning environment, build the foundations for academic success, welcome students and families to the campus community, promote student interactions with faculty and staff, and convey the values and traditions of the new institution" (p. 391). Successful orientation programs can also increase the probability that students will become involved in co-curricular activities and take advantage of available student services (Fox, Zakely, Morris, \& Jundt, 1993).

Other unique benefits have been associated with students' participation in orientation sessions. Wolf-Wendel, Tuttle, and Keller-Wolff (1999) demonstrated that participants in a first-year summer institute orientation program believed that the program facilitated their transition from high school to college in 
academic, social, developmental, and logistical domains. Pascarella, Terenzini, and Wolfle (1986) concluded that participation in orientation programs had an indirect, rather than a direct, effect on academic performance and persistence. The researchers instead discovered that orientation programs had a direct, positive effect on students' social integration and their subsequent commitment to the institution. Mayhew, Stipeck, and Dorow (2011) also found evidence that students' participation in orientation explains greater variance in their social adjustment than in their academic adjustment, further suggesting that some of the greatest benefits to orientation participation may lie within the social domains of campus life.

Within retention literature (Tinto, 1993), the social domains of campus life have been previously associated with students' sense of belonging and subsequent commitment to the institution. Although much is known about sense of belonging as a conceptual idea, Strayhorn (2008) argued that "comparatively few empirical studies estimate the influence of various factors on students' sense of belonging in college" (p. 307). In order to address the gaps in literature regarding both the effectiveness of extended orientations and the factors that influence students' sense of belonging, our present study addresses the following research question: Controlling for additional factors, do first-year students who participated in an extended new student orientation (known as "Welcome Week" at this university) have a greater sense of belonging, higher fall and spring cumulative grade point averages, and higher first-to-second year retention rates than students who did not participate in Welcome Week?

\section{Conceptual Framework: Social Identity Theory and Community Development}

Due to the changes in social identity that many first-year students make as they transition to higher education, the framework chosen for this study is social identity theory, which can explain the process by which first-year students assume identities affiliated with their respective institutions. It is presumed that students who feel a stronger institutional identity, along with greater institutional support, will more likely feel a sense of belonging at their institution and subsequently persist to their second year. Extended new student orientations, in part, can facilitate students' development of a social identity as a college student by introducing students to the college or university's traditions, norms, and values. Additionally, extended new student orientations can offer a strong, supportive foundation for first-year students' transition to higher education by connecting students to the university community and thus increasing their commitment to the community.

Within social identity theory, a social identity is a person's knowledge that he or she belongs to a social group (Hogg \& Abrams, 1988); in the context of higher education, first-year students often check their former high schoolaffiliated identities at the college gates and begin to identify as college students, 
become aligned with a specific institutional identity (e.g., "I am a University of XX student"), and more specifically, begin to address themselves as a campus mascot (e.g. "I am a Tiger").

Social identity theory speculates that identification with a social group occurs in one of two ways: through self-categorization and through social comparison (Stets \& Burke, 2000). In this respect, other people who are perceived as being similar to the individual self are categorized with the self (the in-group), while those who differ from the self are categorized as the outer-group. Identification in a social group can have profound implications on one's cognitive, affective, and behavioral dimensions. Stets and Burke (2000) noted that "having a particular social identity means being at one with a certain group, being like others in the group, and seeing things from the group's perspective" (p. 226). Social group identification is also more or less salient in specific situations, a phenomenon closely tied to the psychological significance of group membership (Stets \& Burke, 2000). In the context of higher education, one may feel a closer affinity with his or her institution of enrollment when engaged in activities that promote school spirit or reinforce the individual's identity alongside a campus mascot. In addition, the greater number of persons to whom one is tied through an identity increases one's commitment to that social identity; seen in this perspective, large-scale events that evoke school spirit or institutional identification (e.g., sporting competitions, matriculation, or convocation) can increase the probability that the social group identity will be activated in those situations.

Social group identification can inform one's sense of belonging to a group or organization; Baumeister and Leary (1995) suggested that social group affiliation may be understood as an individual's need to belong and that "it may be no accident that people seem most likely to be prejudiced against members of groups to which they have little or no opportunity to belong" (p. 521). Social identity theory also supports that people "remain loyal when they feel that their organizations...value and appreciate them" (Tyler, 1999, p. 235). Fuller, Barnett, Hester, and Relyea (2003) also found that individuals' perceived organizational support was positively associated with their organizational commitment. In short, individuals who feel supported by a group tend to have higher self-esteem as a group member, thus increasing their commitment to the group. In higher education, college students who have a strong social identity with an institution and feel supported by the institution may be more likely to have a higher selfesteem as an in-group member, thus increasing their subsequent commitment to the institution.

Indeed, prior research has established that students who feel supported and have a deeper sense of belonging are more likely to persist and graduate (Hausmann, Schofield, \& Woods, 2006). The benefits of having a stronger sense of belonging at an institution also extend into students' academic integration as well; for example, Hausmann, et al. (2006) found that students' adjustment to the academic environment of college is closely tied to their sense of belonging with the college. 


\section{Welcome Week: An Extended New Student Orientation}

There are several ways in which new student orientation programs are designed to foster students' emerging group identities. At the campus examined in this study, the extended new student orientation program (Welcome Week) provides a formal mechanism for sharing university traditions, resources, opportunities, and expectations. The model used in this study consists of a two-day summer orientation followed by a six-day extended orientation. The Welcome Week program was designed to foster a sense of community and social group identity for the incoming class of first-year students, establish campus academic norms and expectations, and encourage first-year students to become involved in their campus community.

The process of creating Welcome Week began in 2003 when the institution wanted to create a common experience for all new students. Designed by over 75 campus stakeholders, the Welcome Week program has several outcomes that connect back to social identity theory; namely, at the end of Welcome Week participation, students should feel a sense of community; have a sense of institutional pride; begin to make meaningful connections with other students, faculty, and staff; and acknowledge individual responsibility to the community, among other outcomes. To that end, the Welcome Week schedule includes specific events to foster institutional identity and develop students' sense of belonging to the campus community. For instance, students attend New Student Convocation, designed to establish class identity, and participate in a "Pride and Spirit" event, in which all 5,000+ members of the first-year class form a giant symbol that represents the university's emblem on the football field. Throughout the Welcome Week experience, students' identities as college students are reaffirmed, and their sense of belonging is encouraged through frequent small group interactions; further, many Welcome Week activities are designed to foster students' social identity as university community members.

Welcome Week is designed to foster and support students' multiple identities by connecting them to others with similar identities; for example, students are connected with others who live in their residence halls, are connected with fellow commuters, become affiliated with a particular major or college, or connect with other students who have similar interests. In addressing students' multiple identities, students ultimately develop a deeper affinity with the institution because students develop social and academic touch points that address their holistic developmental needs.

While many of the Welcome Week's components were designed to foster students' sense of belonging, retention, and academic success, these outcomes were previously unmeasured; therefore, in this study, the authors attempted to determine whether students who participated in Welcome Week had a higher sense of belonging, academic success, and retention compared with students who did not attend the Welcome Week. 


\section{Methods}

This study employed both survey and institutional data to answer our research questions related to sense of belonging, academic achievement, and retention; specifically, we employed survey data (the Student Experience in the Research University survey) to analyze the first three outcomes (students' sense of belonging, fall grade point average, and spring grade point average). In those three models, we sought to control for additional factors derived from survey items, including campus climate, academic engagement, and demographic information not available in institutional records, including students' self-identified social class. In the model predicting our fourth outcome, students' first-to-second year retention, we could only rely upon institutional data, as few non-returners completed the survey.

\section{Instrument}

The Student Experience in the Research University (SERU) survey is based at the Center for Studies of Higher Education and is administered by the University of California-Berkeley. The SERU survey contains nearly 600 individual items focusing on students' academic engagement, civic engagement, global knowledge and skills, and development. As a census survey, the SERU is administered to all undergraduate students enrolled during an academic year.

\section{Participants}

In fall 2009, 5,400 non-transfer first-year students enrolled at a large public university classified by the Carnegie Foundation as having very high research activity. Of those students, 4,629 (85.7\%) participated in Welcome Week College Day activities. All 5,400 first-year students were invited to complete the SERU survey via e-mail, and the response rate was $34.5 \%(n=1,865)$. Table 1 represents the distribution of these students based on their participation in Welcome Week.

\section{Measures}

Of the demographic variables used in the analysis, gender, race, and international status were gathered from institutional data, while first-generation status and social class were collected from students' self-reported survey responses. All of the demographic variables were dummy-coded with " 1 " representing the focal category and " 0 " representing the referent groups. Within the dummycoded race/ethnicity variables, students who identified their race as non-specified were excluded. Students were asked to self-identify their social class through the question, "Which of the following best describes your social class when you were growing up?" and could select one of the following categories: wealthy, uppermiddle or professional-middle, middle-class, working-class, low-income, or poor. 


\section{Demographic Variables of SERU First-Year Respondents by Welcome Week Participation}

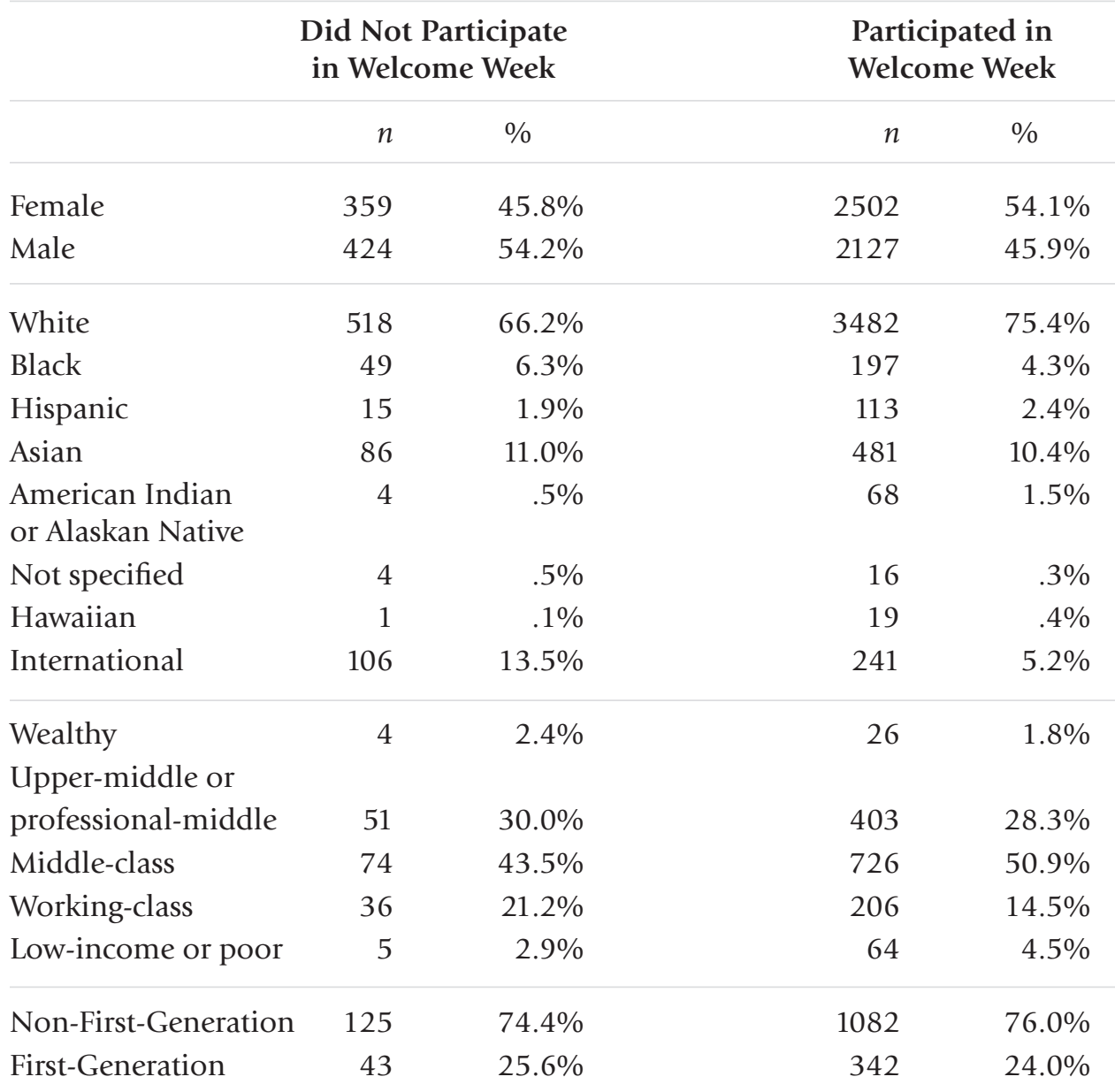

Finally, students' status as first-generation was defined as neither parent having earned a baccalaureate degree and was derived by asking students about their parents' highest attained degree in the United States or in a foreign country.

Additional control variables were used in the analysis, including students' participation in freshman seminars and participation in Access to Success (ATS), an advising community that provides personalized, holistic, and culturally competent advising that advances academic excellence, campus engagement, and professional 
development for students. A total of 1,821 students participated in freshman seminars, with $88.4 \%$ of those students participating in Welcome Week $(n=$ $1,610)$. Additionally, 379 students participated in ATS, with $82.5 \%$ participating in Welcome Week $(n=313)$.

Two additional control factors were created-academic engagement and campus climate-as literature has demonstrated that these factors impact students' sense of belonging. These three factors were developed by conducting a factor analysis on 13 items with oblique rotation (Promax). Campus climate items asked students to rate whether students were respected on campus given their gender, socio-economic status, religious beliefs, political beliefs, sexual orientation, and race/ethnicity. Sense of belonging items asked students to rate whether they felt like they belonged on campus, if they would return to campus, and whether they were satisfied with their social experiences. Finally, academic engagement items asked students to list the frequency with which they interacted with faculty, asked insightful questions in class, or contributed to class discussions during the academic year. Given Kaiser's criteria on three components and the convergence of the scree plot that showed an inflexion that justifies retaining three components, the final analysis retained three components: campus climate, academic engagement, and sense of belonging. These factors had high internal reliability as measured by Cronbach's alpha ( $\alpha=.84$ for academic engagement and sense of belonging and $\alpha=.91$ for campus climate). Factor scores were computed using the regression method and saved as standardized scores with a mean of zero and a standard deviation of one.

To address the second research question regarding students' fall and spring cumulative grade point averages, we again employed the same control variables used in our analysis predicting students' sense of belonging. To address student retention, we scaled back on the use of variables derived from the SERU survey due to the low survey response rate among non-returners. Of the 5,400 first-year students in our dataset, $572(10.6 \%)$ were not retained from their first-to-second year of study. Of those who did not return for their second year, only 89 completed the survey $(15.6 \%)$, severely limiting the number of survey responses with which to examine non-returners; therefore, to answer our question regarding student retention, we relied upon institutionally derived data only, which included gender, race, participation in the ATS program, participation in freshman seminars, spring cumulative grade point average, and whether students lived on campus in residence halls.

\section{Limitations}

Our study has a few limitations that should be addressed. First, in comparing students who participated in Welcome Week and those who did not attend Welcome Week, it is important to consider the potential bias of students who choose to attend Welcome Week; in other words, students who attend Welcome Week may already be high performing students committed to the institution. There is also the potential for inaccuracy of measurement; we used rosters of 
students' participation in one primary Welcome Week event. In addition, any use of students' survey responses entails the same challenge of response bias; for example, among our survey respondents, females and White students were slightly overrepresented compared to the population.

\section{Results}

To address our first research question, multiple linear regression was conducted to examine whether there are differences between Welcome Week participants and non-participants in their sense of belonging, fall/spring cumulative grade point averages, and retention hold when controlling for additional factors. The results suggest that the overall regression predicting sense of belonging was statistically significant, $F(12,1493)=21.82, p<.001$ (Table 2$)$. This model accounts for $14.9 \%$ of the variance in sense of belonging. Welcome Week attendees had a .15 higher sense of belonging than non-attendees when holding other factors constant in the model.

The results also suggest that the regression predicting fall cumulative grade point averages was statistically significant, $F(11,1494)=10.18, p<.001$ (Table 2). This model accounts for $7.0 \%$ of the variance in fall cumulative grade point average. Welcome Week attendees had a .11 higher fall grade point average than

TABLE 2

\section{Regression Models Predicting Sense of Belonging and Fall/ Spring Cumulative Grade Point Averages}

\begin{tabular}{|c|c|c|c|c|c|c|}
\hline \multirow[b]{2}{*}{ Predictor } & \multicolumn{2}{|c|}{ Sense of Belonging } & \multicolumn{2}{|c|}{ Fall GPA } & \multicolumn{2}{|c|}{ Spring GPA } \\
\hline & B & SE & B & SE & B & SE \\
\hline Constant & $-.57 * * *$ & .16 & $3.24 * * *$ & .05 & $3.25^{* * *}$ & .05 \\
\hline Welcome Week & $.15^{*}$ & .08 & $.11^{*}$ & .05 & $.11^{*}$ & .05 \\
\hline Female & -.01 & .05 & .03 & .03 & .03 & .03 \\
\hline Students of Color & -.09 & .07 & $-.17^{* * *}$ & .04 & $-.15^{* * *}$ & .04 \\
\hline International & $-.22 *$ & .10 & .00 & .06 & -.02 & .06 \\
\hline First-Generation & .03 & .06 & -.05 & .04 & -.06 & .03 \\
\hline Working-Class & $-.19 * *$ & .07 & $-.14 * *$ & .04 & $-.14 * *$ & .04 \\
\hline Low-Income & $-.39 * *$ & .13 & $-.33^{* * *}$ & .08 & $-.29 * * *$ & .07 \\
\hline Freshmen Seminar & .05 & .05 & $.07^{*}$ & .03 & $.06^{*}$ & .03 \\
\hline ATS Program & .20 & .12 & -.08 & .07 & -.10 & .07 \\
\hline Campus Climate & $.30 * * *$ & .02 & -.02 & .01 & -.02 & .01 \\
\hline Academic Engagement & $.13^{* * *}$ & .02 & $.04 * * *$ & .01 & $.04 * *$ & .01 \\
\hline Fall term GPA & $.15^{* *}$ & .04 & & & & \\
\hline$R^{2}$ & & $14.9 \%$ & & $7.0 \%$ & & $6.6 \%$ \\
\hline
\end{tabular}

Note. ${ }^{*} \mathrm{p}<.05,{ }^{* *} \mathrm{p}<.01,{ }^{* * *} \mathrm{p}<.001$ 
non-attendees when holding other factors constant in the model. Additionally, the regression predicting spring cumulative grade point averages was statistically significant, $F(11,1495)=9.63, p<.001$ (Table 2). This model accounts for $6.6 \%$ of the variance in spring cumulative grade point average. Welcome Week attendees had a .11 higher spring grade point average than non-attendees when holding other factors constant in the model.

A logistic regression analysis was conducted to predict students' retention using Welcome Week participation, gender, race, international status, participation in freshman seminars, participation in ATS, living in the residence halls, and spring grade point average as predictors. A test of the full model against a constantonly model was statistically significant, indicating that the predictors are reliably distinguished between returners and non-returners $(\chi 2=512.35, p<.001, d f=$ 8 ). Using a Delta-p equation recommended by Cruce (2009), which includes the mean-centered values for the categorical independent variable (in this case, Welcome Week attendance), the data suggest that Welcome Week attendees were $17.2 \%$ more likely to return for the following academic year (Table 3 ).

TABLE 3

\section{Logistic Regression Analysis of the Effects of the Prerequisite System on Students' Retention from Year One to Year Two}

\begin{tabular}{lrrrrr} 
Predictor & B & SE & Wald's $\chi^{2}$ & $d f$ & $\begin{array}{c}\mathrm{e} \beta \\
\text { (odds ratio) }\end{array}$ \\
\hline Welcome Week & $.25^{*}$ & .13 & 3.75 & 1 & 1.28 \\
Female & $-.26^{* *}$ & .10 & 6.82 & 1 & .77 \\
Students of Color & .10 & .13 & .53 & 1 & 1.10 \\
International & .31 & .21 & 2.28 & 1 & 1.37 \\
Freshmen Seminar & .18 & .11 & 2.76 & 1 & 1.19 \\
ATS & $1.71^{* * *}$ & .31 & 30.92 & 1 & 5.53 \\
Dorm & .08 & .13 & .37 & 1 & 1.08 \\
Spring GPA & $1.24^{* * *}$ & .06 & 390.85 & 1 & 3.44 \\
Constant & $-1.73^{* * *}$ & .22 & 63.91 & 1 & .18 \\
\hline
\end{tabular}

Note. ${ }^{*} R^{2}=.09$ (Cox \& Snell), .19 (Nagelkerke). ${ }^{*} \mathrm{p}<.05 ;{ }^{* *} \mathrm{p}<.01 ;{ }^{* * *} \mathrm{p}<.001$

\section{Discussion and Recommendations}

Our study found evidence for the positive benefits of participation in extended orientations. Our results suggest that Welcome Week participants had higher fall and spring semester cumulative grade point averages, retention to their second year, and sense of belonging when controlling for additional factors, including 
demographics, campus climate, academic engagement, and participation in academic programs. Connecting to our conceptual framework, we surmise that participation in the extended new student orientation enhanced students' social identities as college students within this particular institution, thereby increasing their sense of belonging, academic performance, and retention.

The following recommendations are made for practice. First, we recommend that institutions consider developing an extended new student orientation model as an alternative to a one, two, or three-day model. Several benefits emerged with the addition of this new model; for instance, Welcome Week incorporated some of the content traditionally included in orientation and reduced the "information overload" problems frequently cited by orientation staff and participants.

Additionally, Welcome Week minimized the workload for advising staff and others who were already working at full capacity during this time period; furthermore, Welcome Week significantly expanded leadership development opportunities available to upper division students.

When developing an extended orientation program, institutions need to identify desired outcomes and create programming that maps those specific outcomes. Being intentional with program content creates a more meaningful experience for students and can lead to increased buy-in and support from campus stakeholders. It is important to invest the time and energy to meet with many stakeholders, identifying issues and concerns of specific units and attempting to address those through the planning process.

It is also important that administrators and practitioners recognize that a one-size-fits-all approach to developing orientation programs will not prove effective (Deggs \& Associates, 2011). This is especially the case when it comes to helping students develop their college student identity along with an institutional affiliation, as every college and university is unique. Additionally, extended new student orientation programs should offer small group discussions and reflection time so students can process their transitional and developmental experience individually. Further, it is important that colleges and universities work to help a wide variety of students feel like they belong on campus, a challenge that involves everything from small programmatic efforts to creating a welcoming campus climate for students from diverse backgrounds. Some of these steps can be undertaken in new student orientation sessions, which are often some of the most significant primary interactions students have with the campus environment.

Branding new cohorts of first-year students as part of a "Class of 20XX" is an important part of the transition and identity development process. Such branding creates a sense of belonging to the class as a social group and also reinforces the importance of graduation within a specific timeline. At this institution, "Class of 20XX" t-shirts and tassels are distributed at Convocation, and the university president emphasizes students' class identity at that event. Such program elements reinforce social group identity through branding.

Extended orientations can help students make connections and begin to establish meaningful relationships on campus; these relationships can be facilitated in small group experiences. Mann, Andrews, and Rodenburg (2010) 
noted that students may feel more connected to the institution if they experience orientation in a smaller peer group-especially those led by peer leaders-which allows students to develop meaningful social connections with other students. In the crucial first weeks of campus, first-year students should also be intentionally and thoughtfully connected with a variety of individuals who can support their transition to college life, including advisers, faculty, and student services staff.

\section{Conclusion}

This study sought to examine the effect of first-year students' participation in an extended new student orientation program. The results suggest that students who participated in Welcome Week had a greater sense of belonging, higher academic success, and greater retention rates than students who did not attend Welcome Week. Our findings support the ongoing importance of new student orientation programs and support the potential effectiveness of extended new student orientations in particular.

\section{References}

Barefoot, B. O. (2005). Current institutional practices in the first college year. In M. Lee Upcraft, J. N. Gardner, \& B. O. Barefoot, \& Associates (Eds.), Challenging and supporting the first-year student: A handbook for improving the first year of college (pp. 47-63). San Francisco, CA: Jossey-Bass.

Baumeister, R. F., \& Leary, M. R. (1995). The need to belong: Desire for interpersonal attachments as a fundamental human motivation. Psychological Bulletin, 117(3), 497-529.

College Board. (2011). How four-year colleges and universities organize themselves to promote student persistence: The emerging national picture. New York, NY: The College Board Advocacy \& Policy Center.

Cruce, T. M. (2009). A note on the calculation and interpretation of the Delta-p statistic for categorical independent variables. Research in Higher Education, $50(6), 608-622$.

Deggs, D., \& Associates. (2011). Students' adjustment to college: A comparison of orientation program attendees and non-attendees. The Journal of College Orientation and Transition, 18(2), 45-50.

Fox, L., Zakely, J., Morris, R., \& Jundt, M. (1993). Orientation as a catalyst: Effective retention through academic and social integration. In M. Lee Upcraft, R. H. Mullendore, B. O. Barefoot, \& D. S. Fidler (Eds.), Designing successful transitions: A guide for orienting students to college (Monograph No. 13) (pp. 49-59).

Columbia, SC: University of South Carolina, National Resource Center for the First-Year Experience. 
Fuller, J. B., Barnett, T., Hester, K., \& Relyea, C. (2003). A social identity perspective on the relationship between perceived organizational support and organizational commitment. Journal of Social Psychology, 143(6), 789-791.

Gardner, J. N. (1986). The freshman-year experience. The Journal of the American Association of Collegiate Registrars and Admissions Officers, 61(4), 261-274.

Hausmann, L. R. M., Schofield, J. W., \& Woods, R. L. (2006). Sense of belonging as a predictor of intentions to persist among African American and White firstyear college students. Research in Higher Education, 48(7), 803-839.

Hogg, M. A., \& Abrams, D. (1988). Social identifications: A social psychology of intergroup relations and group processes. London, England: Routledge.

Mann, A., Andrews, C., \& Rodenburg, N. (2010). Community college orientation and transition programs. In J. A. Ward-Roof (Ed.), Designing successful transitions: A guide for orienting students to college (Monograph No. 13, 3rd ed.) (pp. 43-60). Columbia, SC: University of South Carolina, National Resource Center for the First-Year Experience and Students in Transition.

Mayhew, M. J., Stipeck, C. J., \& Dorow, A. J. (2011). The effects of orientation programming on learning outcomes related to academic and social adjustment with implications for transfers and students of color. Journal of the First-Year Experience \& Students in Transition, 23(2), 53-75.

Mullendore, R. H., \& Banahan, L. A. (2005). Designing orientation programs. In M. Lee Upcraft, J. N. Gardner, \& B. O. Barefoot, \& Associates (Eds.), Challenging and supporting the first-year student: A handbook for improving the first year of college (pp. 391-409). San Francisco, CA: Jossey-Bass.

National Orientation Directors Association (2011). NODA Databank. Retrieved from http://noda.orgsync.com/about_databank.

Pascarella, E. T., \& Terenzini, P.T. (1991). How college affects students: Findings from twenty years of research. San Francisco, CA: Jossey-Bass.

Pascarella, E. T., Terenzini, P. T., \& Wolfle, L. M. (1986). Orientation to college and freshman year persistence/withdrawal decisions. Journal of Higher Education, $57(2), 155-175$.

Strayhorn, T. L. (2008). Sentido de pertenencia: A hierarchical analysis predicting sense of belonging among Latino college students. Journal of Hispanic Higher Education, 7(4), 301-320.

Stets, J. E., \& Burke, P. J. (2000). Identity theory and social identity theory. Social Psychology Quarterly, 63(3), 224-237.

Tinto, V. (1993). Leaving college: Rethinking the causes and cures of student attrition (2nd ed.). Chicago, IL: University of Chicago Press.

Tyler, T. R. (1999). Why people cooperate with organizations: An identity-based perspective. In R. I. Sutton and B. M. Staw (Eds.), Research in organizational behavior (Vol. 21) (pp. 201-247). Greenwich, CT: JAI Press.

Wolf-Wendel, L. E., Tuttle, K., \& Keller-Wolff, C. M. (1999). Assessment of a freshman seminar transition program in an open-admissions institution. Journal of the First-Year Experience, 11(2), 7-32. 